\title{
Editorial
}

\section{Los acuerdos de Nueva York en el tema económico social: perspectivas de transformación}

El 31 de diciembre de 1991 el Gobierno de El Salvador y el Frente Farabundo Marli para la Liberación Nacional (FMLN), bajo los auspicios del Secretario General de las Naciones Unidas, Javier Pérez de Cuéllar; firmaron en Nueva York el acla que eslablece los acuerdos fundamentales para el logro definitivo de la paz en El Salvador.

Los acuerdos dan fin a más de 11 anos de guerra civil y abren una nueva etapa en la historia del país, una elapa de reconstrucción de to deslruido por el conllicto y la crisis; y de construcción de las bases reales de la democracia y el desarrollo económico y social: que han sido las grandes ausentes en la historia del país.

El acta firmada en Nueva York establece acuerdos en los campos político, militar, jurídico, derechos humanos y económico social. Eslos acuerdos abren espacios importanles para transiormar una sociedad excluyente, marginadora, antidemocrática y militarizada; el relo está abierto podemos Iransitar hacia un nuevo orden económico y social donde predomine la democracia, donde se imponga la sociedad civil y donde realmente se enfrenten las causas que dieron origen a la crisis y el conflicto.

En esta perspectiva, es necesario analizar los acuerdos en el tema económico social, para ver las posibilidades de avanzar en transformaciones importantes que viabilicen el desarrollo socio-económico de El Salvador. Entre los componentes del acuerdo en este lema están: el problema agrario sobre las tierras en las zonas conflictivas, sobre las 
lierras ocupadas, sobre el crédito al sector agropecuario, sobre las medidas para aliviar el costo social de los programas de ajuste estructural; sobre la modalidad para la cooperación externa directa para proyectos de desarrollo de las comunidades, sobre el toro de concertación económico-social y sobre el plan de reconstrucción nacional.

Para analizar el conjumlo de estos acuerdos en el tema económico social es necesario partir de la apreciación global que el componente de la desmilitarización o el desmontaje del aparato militar ha sido el punto fundamental del acuerdo, esto tiene un sentido para las partes directamente involucradas en el conflicto y para la sociedad civil que ha sufrido la imposición de las polílicas económicas y de estrategias de desarrollo que privilegian a las minorías amparándose en un poder militar al servicio de éstas.

Especílicamente analizando los acuerdos en el tema económico-social estos privilegian la solución de una serie de problemas vinculados al agro salvadorefio y concretamente al problema del acceso a la tierra al campesino. En esta perspecliva podemos identiticar algunos puntos que demuestran la ineficiencia en el manejo de este problema por parte del actual gobierno; estos se relieren a las tierras excedentes a las 245 ha. que según la Constitución Política deberían ser transferidas a los campesinos hace algún tiempo, las tierras propiedad del Estado que lampoco han sido elicientemente distribuidas y la capacidad del Eslado de comprar tierras, la cual no se ha logrado realizar a pesar que el Estado cuenta con recursos suficientes para desarrollar esta acción de compra y venta por medio del banco de tierras, (el cual ha demostrado su inoperancia en más de un año de estar funcionando).

En general podemos sefialar que la política agraria del gobierno en cuanto al problema de las tierras se reliere ha sido manejado ineficientemente, asi lanto FINATA, ISTA, y banco de tierras requieren de una redelinición de su papel en este campo y se necesita a su vez incorporar a los sectores campesinos en un nuevo marco inslilucional que enfrente seriamente este problema histórico en el pais.

El punto lundamental para enfrentar el problema de la tierra está en el acuerdo sobre las tierras en las zonas conflictivas, este aspecto es importante desde el punlo de vista político para el FMLN, ya que garantiza su inlluencia sobre la población en esta área; pero también es relevante desde el marco del desarrollo económico y social de amplias zonas donde se ubican gran cantidad de población que ha sufrido drásticamente los efectos del conflicto, y que tienen grandes potencialidades para superar sus acluales necesidades y convertirse en importanles agentes del desarrollo nacional. 
Los problemas en el acuerdo sobre las tierras en las zonas conflictivas, se encuentran, en el marco de las negociaciones que se deberán establecer entre los propielarios y los actuales poseedores de la tlerra, en este marco la negociación es directa y el precio de la tierra se define por el mercado. Existe también la posibilidad de que el propietario no eslé interesado en vender su tierras y trasladaría la solución al Eslado, el cual procurara (termino muy indefinido), reasentar a los campesinos en tierras disponibles para ellos. Ciertamente el proceso de acceso a la tierra al campesino ha sido siempre conlliclivo; este nuevo mecanismo no esla exento de esto, pero cabe al gobierno una gran responsabilidad para que éste se desarrolle de la mejor manera posible, a fin de evilar la conirontación y la inestabilidad social.

El úllimo acuerdo sobre las tierras esta referido a aquellas que fueron ocupadas por los campesinos a principios de ano y cuya resolución se dejó pendienle, de tal forma que ésta se iniroduce en esle acuerdo obligando a una negociación sobre estas tierras a las partes involucradas.

En su conjunlo el acuerdo sobre tierras puede significar un importante avance el se desarrolla en todos sus contenidos y efectivamente; asi también podriamos calificarlo de una nueva elapa de la reforma agraria, asi como un nuevo tipo de reforma; las tierras involucradas no son fácilmenle cuanlificables en este momento pero podríamos hablar de más de 150 mil hecláreas que estarian comprendidas en los dislintos aspectos de esle lema.

Articulado a este tema exislen acuerdos sobre crédito agricola a los campesinos y pequefios productores, participación de ellos en los organismos financieros de apoyo como FIGAPE, FEDECREDITO. Fondo de Garantía Agropecuario y Banco de Fomento Agropecuario, (lanto para el diseño como para la administración de los recursos), asistencia técnica amplia, cooperación internacional, creación del código agrario, creación de una comisión especial para resolver el problema de las tierras en las zonas confliclivas. elc. Existen por lo tanto condiciones importantes para resolver el problema agrario en algunas de sus partes sutanciales. Dependerá de las partes y de las organizaciones campesinas el que éslas se resuelvan para avanzar seriamente en la solución de los graves problemas del pais.

El segundo punto en imporlancia en el acuerdo de Nueva York sobre el tema económico y social es el reterido al Foro de Concertación Económico y Social; aquí se establecen mecanismo importantes para su creación y la participación de los sectores sociales. Este foro es considerado por algunos como la segunda fase de la negociación. 
En este acuerdo está muy bien delinido la convocatoria por parte de COPAZ, la composición de las fuerzas más representalivas en el sector laboral y empresarial y la representación de atto nivel del gobierno. Lo que no está muy claro es la agenda de temas; ya que en un principio el acuerdo senala que la creación del foro tiene como objetivo lograr un conjunto de amplios acuerdos tendientes al desarrollo económico y social del pais, en beneficio de todos sus habilantes; lo cual hace suponer la posibilidad de disculir y concertar sobre diversos temas vinculados al desarrollo nacional. Más adelanle se senala que el gobierno propondrá al foro: la revisión del marco legal en maleria laboral, el análisis de la siluación de las comunidades marginales urbanas y suburbanas y la concerlación de medidas tendientes a aliviar el cosio social del programa de ajusle estructural. Al final el documento eslablece que el foro definirá su esinuctura operativa y las temáticas de discusión y concertación.

Si bien no parece quedar claro qué aspectos podrán disculirse y concertar; consideramos que lo más importante en esto es que se garantice que el loro sea el mecanismo idóneo para ir enfrentando los graves problemas económicos y sociales, bajo la modalidad de la concertación y la búsqueda de consensos. El que se logre inslilucionalizar este inslrumento de consenso de la sociedad es un logro fundamenlal ya que nadie podrá establecer medidas sin anles haberlas discutido y concertado. A su vez es necesario que esle mecanismo de concerlación tenga una duración lo suficientemenle imporlante para que los distinlos sectores sociales se manifiesten propositivamente a la solución de los problemas nacionales y que se logren acuerdos sobre él; esto seria muy beneficioso para la conslrucción de un proyecto de nación y de desarrollo nacional donde cada uno es participe de los beneficios y los sacriticios que ella implica.

Otra de las áreas del acuerdo se refiere a las medidas para aliviar el costo social del programa de ajuste estructural; aqui si bien no se logra modificar el programa del gobierno, se establecen por lo menos algunos mecanismos institucionales y legales que eviten las prácticas monopólicas y la delensa del consumidor; esto supone profundizar en marcos propositivos sobre la privatización de las empresas publicas y sobre la creación de una ley y procuraduria de delensa del consumidor. Tarea importanle a desarrollar por los distinlos sectores sociales. El fortalecimiento de los programas de compensación social es el acuerdo obvio en esla parte.

Por último, uno de los componentes fundamentales para el desarrollo en el mediano y largo plazo es el acuerdo sobre el plan de reconstrucción nacional. En ésle se establece que el Gobiemo de El Salvador 
presentará al FMLN su plan de reconstrucción, con la finalidad que éste le haga recomendaciones y sugerencias a ser tomadas en cuenla y que refleja la volunlad colectiva del país. Es decir si bien explicitamente no se acepla un plan concertado; la realidad social del país impone la concertación para que el plan de reconsirucción sea viable.

En esle acuerdo se deline los grandes lineamientos de la reconstrucción; desarrollo integral de las zonas alectadas por el conflicto, atención a las necesidades inmediatas de la población afectada y de los excombatiemles de ambas partes y la reconstrucción de la infraestructura dahada; aqul habría que anadir la construcción de nueva infraestructura social y para el desarrollo de las zonas y en benelicio de la población, ya que anles y duranle el cońlicto poco se hizo por crear esta infraestruictura.

En el marco de la reconsinucción uno de los agentes lundamentales será el PNUD, el cual tiene un amplio mandato de las partes para: manejar los londos de la reconstrucción, movilizar el apoyo externo, preparar proyectos y programas, colaborar con el gobierno para compatibilizar el plan con las actividades de los organismos no gubemamentales, dar asistencia técnica, etc. Papel importante en el proceso de construir una nueva nación sobre bases más firmes y solidas de desarrollo y democracia.

Finalmente, el acuerdo en el campo económico y social es muy imporlante, en tanlo crea mecanismos y espacios para la discusión, la reflexión y la participación propositiva de los distinlos sectores sociales en la solución de los graves problemas nacionales. Entendemos algunas limilaciones del acuerdo especialmente en las posibilidades de modificar el actual programa de gobierno y de redelinir su polílica económica. Pero consideramos que los mecanismos eslán abierlos para construir este nuevo proyecto de desarollo económico y social de las mayorías y para las mayorías. El reto es de todos. 